\section{sciendo}

DOI: 10.2478/BIPMF-2021-0002
BULETINUL INSTITUTULUI POLITEHNIC DIN IAŞI

Publicat de

Universitatea Tehnică „Gheorghe Asachi” din Iaşi Volumul 67 (71), Numărul 1, 2021

Secţia

\title{
CHAOS AND SELF-STRUCTURING IN BIOLOGICAL SYSTEMS
}

\section{VLAD GHIZDOVĂȚ ${ }^{1}$, CIPRIANA ŞTEFĂNESCU ${ }^{1, *}$, MIHAI MARIUS GUȚU ${ }^{1}$, DECEBAL VASINCU ${ }^{2}$ and TEODOR-MARIAN IONESCU ${ }^{3}$}

\author{
1"Grigore T. Popa" University of Medicine and Pharmacy, \\ Faculty of Medicine, Biophysics and Medical Physics Department, Iaşi, Romania \\ 2"Grigore T. Popa" University of Medicine and Pharmacy, \\ Faculty of Dental Medicine, Biophysics Department, Iaşi, Romania \\ 3"Grigore T. Popa" University of Medicine and Pharmacy, \\ Faculty of Medicine, Iaşi, Romania
}

Received: February 9, 2021

Accepted for publication: March 30, 2021

Abstract. Assuming that the structural entities of a complex system assimilated to a biological structure move on fractal curves, the biological systems dynamics are studied. Our theoretical model shows that oscillations via self-similarity can be achieved in these types of systems. Furthermore, some potential applications of the interferential property of biological systems are presented, in emerging interdisciplinary fields such as molecular communication.

Keywords: biological systems; fractals; self-similarity; non-linear dynamics.

\section{Introduction}

Scientist have been studying the various types of complex systems by employing basic theories, mostly based on physics notions and also computer simulation. From the vast array of complex systems we can mention human

*Corresponding author; e-mail: cipriana.stefanescu@umfiasi.ro

This is an Open access article licensed under the Creative Commons Attribution-Non Commercial - No Dericatives 4.0 International License (CC BY-NV-ND 4.0) 
societies, ecosystems, biological organisms, trading markets, and the list can go on (Mitchell, 2009). The evolution of such systems cannot be predicted only by analyzing the behaviors of its individual elements or simply by suuming their behavior. A complex system behavior must be determined by the way in which its elements interact in order to influence the global behavior. Some of the crucial properties of these systems are are emergence, self-organization, and adaptability (Winfree, 2000). Therefore, theoretical models that describe the complex systems dynamics can be very hard to implement and improve (Mitchell, 2009). However, this problem can be simplified if we take into account the fact that the interaction process' complexity implies various temporal scale resolutions, and also that the evolution of patterns involves different freedom degrees (Badii and Politi, 1997). Because non-differentiability is a universal property of complex systems, it is necessary, in our opinion, to construct a non-differentiable physics. Thus, if we consider that nondifferentiability replaces the complexity of interactions, we can find that using all of the quantities present in standard physics (differentiable physics) is no longer necessary (Nottale, 1993; Nottale, 2011).

Living systems are inherently complex ones. A relevant example can be found in the cell. Cell is a biosystem with all functional characteristics of biosystems. Cell is not a static structure but a complex steady-state system. Being the result of an evolution, it has informational character, integrality, has a self-regulated evolution governed by a program and respecting thermodynamical principles, energy conservation and increasing entropy principles (Stefanescu and Rusu, 2008). The <program > is dictated by a physiological internal clock, named the cell cycle. The cycle encompasses the life cycle of the cell in an orderly sequence of events: the cell rises, doubles its chromosomes and, then divide into two identical cells. There is no doubt that the cell cycle is the most important life processes in which non-linear dynamics plays an essential role (Romond et al., 1999). Depending on the type of organism involved, the cellular cycle duration ranges between 2-3 hours (single cell organism) to 24 hours (culture mammal cells). Based on the degree of differentiation, the more complex the differentiation, the more different the cycle is. Single cell organisms tend to divide nonstop until they occupy all the space and consume all the environment resources. In case of complex organisms, cellular cycle may vary from a few days to centuries depending on the cell type (hematogenous bone marrow cells divide continuously, while neurons may survive from the beginning to the end of the individual's life). Any type of modification in the cellular cycle (including temporal control) may lead to loss of the cellular characteristics and uncontrolled proliferation - cancer (Serban et al., 2008). The origin of cancers is monoclonal, in which a single cell is transformed, then it divides and eventually determines genetic instability. Due to this instability, cancers are heterogenous and composed from polyclonal population. Therefore, cancer can also be described as a multifactorial "genetic" 
disease in the sense that multiple molecular changes of oncogenes and antioncogenes have to collaborate to determine this pathology (Arlet et al., 2011). The term cancer is usually assigned to all malignant tumors which are characterized by fast extension through abnormal proliferation of transformed cells, that invade local tissues and have the tendency to generalize by production of secondary distal tumors (metastasis) (Rusu, 2007). Diagnosing cancer in the early stages is difficult. Not even the immune system can differentiate the abnormal cell from the normal one until it is too late and the damage is already done (local invasion, metastasis etc). To that end understanding all triggering factors of different cell life steps and the non-linear processes that derive from them will potentially help therapy of uncontrolled cell dynamics in cancer.

Thus, taking into account the above presented facts, nondifferentiability seems well suited for analyzing and describing living systems. We quote (Nottale, 2011): "In living systems morphologies are acquired through growth processes. One can attempt to describe such a growth in terms of an infinite family of virtual, fractal and locally irreversible, fluid-like trajectories. Their equation can therefore be written under the form of a fractal geodesic equation, then it can be integrated as a Schrödinger equation or, equivalently, in terms of hydrodynamics-type energy and continuity equations including a quantum-like potential (...) This could be an interesting advantage for taking into account the organization of living systems in terms of welldefined bauplans and the punctuated evolution of species whose evolutive leaps go from one organization plan to another" (Nottale, 2011).

\section{Methods}

Assuming that the structural units of a complex system, which has been assimilated to a biological structure, move on fractal curves, the biological geodesics equation (Mandelbrot, 1983) has the following form:

$$
\frac{\hat{d} \boldsymbol{V}}{d t}=\frac{\partial \boldsymbol{V}}{\partial t}+\boldsymbol{V} \cdot \nabla \boldsymbol{V}-i D(d t)^{\left(2 / D_{F}\right)-1} \Delta \boldsymbol{V}=0
$$

where $V$ is the complex speed field of the structural entities of a complex system assimilated to a biological structure, $D$ is the fractal-non-fractal transition coefficient (Mandelbrot, 1983), $d t$ is the scale resolution and $D_{F}$ the fractal dimension of the non-differentiable curves.

Neglecting the convection $\boldsymbol{V} \cdot \nabla \boldsymbol{V}$, Eq. (1) takes the form:

$$
\frac{\partial \boldsymbol{V}}{\partial t}-i D(d t)^{\left(2 / D_{F}\right)-1} \Delta \boldsymbol{V}=\mathbf{0}
$$


or, separating the scale resolutions,

$$
\frac{\partial \boldsymbol{v}}{\partial t}-D(d t)^{\left(2 / D_{F}\right)-1} \Delta \boldsymbol{u}=0
$$

for the differentiable scale, and

$$
\frac{\partial \boldsymbol{u}}{\partial t}-D(d t)^{\left(2 / D_{F}\right)-1} \Delta \boldsymbol{v}=0
$$

for the fractal scale. These velocity fields can be separated by applying (2) and (3) to the $\Delta$ operator, i.e.

$$
\frac{\partial}{\partial t}(\Delta \boldsymbol{v})-D(d t)^{\left(2 / D_{F}\right)-1} \Delta^{2} \boldsymbol{u}=0
$$

and

$$
\frac{\partial}{\partial t}(\Delta \boldsymbol{u})+D(d t)^{\left(2 / D_{F}\right)-1} \Delta^{2} \boldsymbol{v}=0
$$

If we substitute the dissipative terms via Eq. (1) separated on resolutions scales, the Kirchhoff-type equations (Coleman et al., 1993) results:

$$
\left(\frac{\partial^{2}}{\partial t^{2}}+D(d t)^{\left(4 / D_{F}\right)-2} \Delta^{2}\right)\left(\begin{array}{l}
\boldsymbol{v} \\
\boldsymbol{u}
\end{array}\right)=\left(\begin{array}{l}
0 \\
0
\end{array}\right)
$$
notations

In the one-dimensional case, the above-written equations, by means of

$$
\begin{aligned}
& \frac{x}{L}=\bar{\xi}, \frac{t}{T}=\bar{\tau}, \frac{L^{4}}{T^{2}}=D^{2}(d t)^{\left(4 / D_{F}\right)-2}, \\
& (V ; U) \equiv \overline{\mathrm{K}}_{i}(\bar{\xi}, \bar{\tau}), i=1,2
\end{aligned}
$$

take the unitary form (Audoly and Neukirch, 2005):

$$
L^{4} \frac{\partial^{4} \overline{\mathrm{K}}_{\mathrm{i}}}{\partial \bar{\xi}^{4}}+T^{2} \frac{\partial^{2} \overline{\mathrm{K}}_{\mathrm{i}}}{\partial \bar{\tau}^{2}}=0
$$

After this, we can impose „clamping” conditions at $\bar{\xi}=1$ for Eq. (9):

$$
\frac{\partial^{2} \overline{\mathrm{K}}_{\mathrm{i}}(1, \bar{\tau})}{\partial \bar{\xi}^{2}}=0, \frac{\partial^{3} \overline{\mathrm{K}}_{\mathrm{i}}(1, \bar{\tau})}{\partial \bar{\xi}^{3}}=0
$$

and for boundary conditions at $\bar{\xi}=0$ : 


$$
\overline{\mathrm{K}}_{\mathrm{i}}(0, \bar{\tau})=0, \frac{\partial \overline{\mathrm{K}}_{\mathrm{i}}(0, \bar{\tau})}{\partial \bar{\xi}}=0
$$

If these four boundary conditions in $\bar{\xi}$ are associated with the two initial ones

$$
\overline{\mathrm{K}}_{\mathrm{i}}(\bar{\xi}, 0)=\overline{\mathrm{K}}_{i 0}, \frac{\partial \overline{\mathrm{K}}_{\mathrm{i}}(\bar{\xi}, 0)}{\partial \bar{\tau}}=0
$$

this can imply a unique solution $\overline{\mathrm{K}}_{\mathrm{i}}(\bar{\xi}, \bar{\tau})$ to Eq. (9) - see Fig. 1.

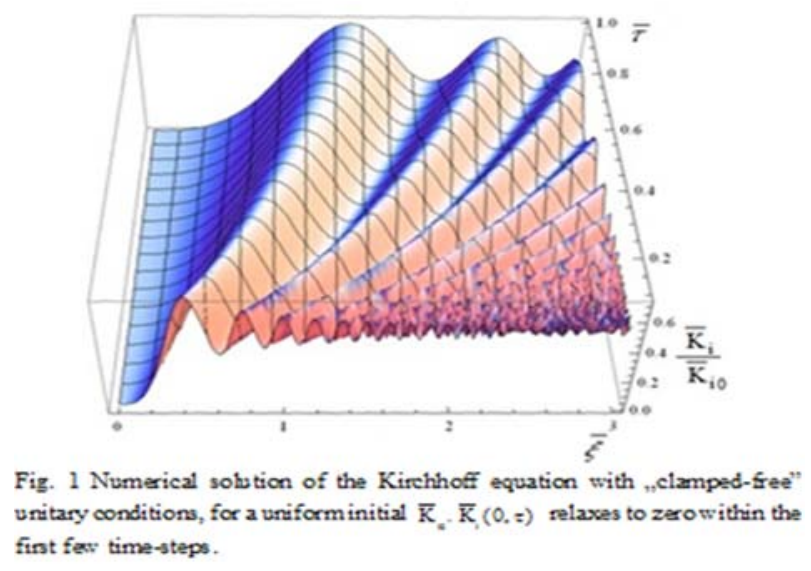

\section{Results and Discussions}

In the absence of convection, oscillations via self-similarity are induced in a complex system associated to a biological structure. Our theoretical results are in good agreement with the experimental ones (Cretan et al., 2007; Gurlui et al., 2008). Thus, we can highlight the interferential properties of the biological medium, which possesses both the biological "multivalent logic" (the DNA code) and the corresponding "software" (biological neural network). A complete understanding of these logical elements, used by living matter and its biological entities, and the ways in which they interconnect, can prove to be very valuable in developing future biophysical research topics.

In such context, we can observe that molecular communication in biological systems is emerging as a promising field of research, which could lead to the development of communication networks between nanomachines, by increasing their functionalities and also by paving the way for new potential applications (Hasan et al., 2014). For better efficiency and biocompatibility, communication systems must be designed by integrating components which can be found in nature. As a result, these types of communication systems must 
include at least one nanotransmitter which 'writes' information into molecules (for example, ions or DNA molecules). These molecules will subsequently be transported to the receiver and then decoded. Severel models for molecular communication can be found in literature, from which we can mention: molecular diffusion of information molecules (Pierobon and Akyildiz, 2010) or models using active carriers such as bacteria (Cobo and Akyildiz, 2010). As an example, because of their specific biological properties, bacteria can be considered a possible information messenger for molecular communication, the corresponding communication networks being named as bacterial nanonetworks (Luo et al., 2014; Aram et al., 2014). One such important characteristic of bacteria is their ability to move between locations and carry the information encoded in DNA molecules. However, like in the case of other organisms, it has been found that bacteria have complex social interactions governing their colonies. These social characteristics allow bacteria to evolve through various variating (often hostile) environmental conditions by using cooperative and non-cooperative behaviors.

\section{Conclusions}

In this paper we assumed that, from a morpho-functional perspective, any biological structure can be a fractal, in the Mandelbrot definition. Thus, we obtained a mathematical model which describes the "dynamics" of such systems. This model has been based on an extended version of the Scale Relativity Theory, specifically the one in which the motions of a complex (biological) system's structural entities take place on continuous and nondifferentiable curves.

In our opinion, the "differentiation and specialization" process of any biological structure is based on the chaos/order alternance. This alternance is defined by the living matter multivalent logic and its communication codes. The presence of oscillations in biological systems further shows that they can be defined by order and disorder. Both these effects are the source of the biological systems evolution. The fact that the oscillation field holds interferential properties implies self-similarity (holography).

Therefore, by using this fundamental property (interferentiality) communication at nanoscale can be enabled, and by connecting molecular nanonetworks to the Internet, new opportunities for state-of-the-art smart cities and healthcare applications could be capitalized. The most important fields where these new researches can manifest are:

i) Environmental sensing: there is a permanent search for more accurate and efficient environmental sensing techniques, such as the early detection of pathogens that may damage crops or even live stocks. Because bacteria are widely spread in the environment, they can be used as information 
carriers between nano sensors, with the purpose of collecting information at a fine granular scale (Akyildiz et al., 2008).

ii) Biofuel quality monitoring: one of the most efficient and cost-free alternative sources of energy is converting biomass into fuel. Several research studies show how engineered bacteria could turn glucose into hydrocarbon which is identical to commercial fuel, due to their structural properties (Balasubramaniam and Lio, 2013). Therefore, bacterial nanonetworks may improve the biofuel production quality, providing at the same time efficient quality control.

iii) Personalized health-care: early disease detection in patients is a major challenge for modern physicians. This can improve the treatments of specific conditions and prevent further disease spreading. Since bacteria are found in the gut flora, inserting such nanonetworks into the intestine can lead to fine granular sensing at molecular scale. Moreover, bacterial nanonetworks can also provide new ways of targeting specific drug deliveries.

This work is part of a new theoretical approach for understanding the various behaviors of biological systems based on non-linear dynamics. As we can see from Laurent Nottale's recent work, this theoretical framework can be applied to the processes of morphogenesis and the emergence of prokaryiotic and eukaryiotic cellular structures (Nottale, 2008). Using the principles of the Scale Relativity Theory (Nottale, 1993; Nottale, 2011), the evolutionary, developmental, biochemical and cellular theories can be looked upon from a new perspective, thus giving rise to possible applications for the analysis and management of biological systems and their properties (Nottale, 2013).

\section{REFERENCES}

Akyildiz I.F., Brunetti F., Blazquez C., Nanonetworks: A New Communication Paradigm, Computer Networks, 52, 2260-2279 (2008).

Aram V., Iranmanesh A., Majid Z.A., Spider Representation of DNA Sequences, J. Comput. Theor. Nanosci., 11, 418-420 (2014).

Arlet J.B., Aron-Wisknwsky J., Attias D., Blan F.X., Bertolus C., Deffieux X. et al., Le Book des ECN, translated in Romanian, Cluj-Napoca, Medical University Publishing House (2011).

Audoly B., Neukirch S., Fragmentation of Rods by Cascading Cracks: Why Spaghetti Does Not Break in Half, Physical Review Letters, 95, 095505 (2005).

Badii R., Politi A., Complexity: Hierarchical Structure and Scaling in Physics, Cambridge, Cambridge University Press (1997).

Balasubramaniam S., Lio P., Multi-Hop Conjugation-Based Bacteria Nanonetworks, IEEE Transactions on NanoBioscience, 12, 47-59 (2013).

Coleman B.D., Dill E.H., Lembo M., Lu Z., Tobias I., On the Dynamics of Rods in the Theory of Kirchhoff and Clebsch, Arch. Rational Mech. Anal., 121, 339-359 (1993). 
Cobo L.C., Akyildiz I.F., Bacteria-Based Communication in Nanonetworks, Nano Communication Networks, 1, 244-256 (2010).

Cretan M.I., Grigoras S., Hanganu C.L., Stamate V.-C., Ianus G., Wear of Human Joint Devices of Ultra-High-Molecular-Weight Polyethilene (UHMWPE) a Result of Mecanical Compression, Materiale Plastice, 3, 217-220 (2007).

Gurlui S., Agop M., Nica P., Ziskind M., Focşa C., Experimental and Theoretical Investigations of Transitory Phenomena in High-Fluence Laser Ablation Plasma, Phys. Rev. E, 78, 026405 (2008).

Hasan M., Hossain E., Balasubramaniam S., Koucheryavy Y., Social Behavior in Bacterial Nanonetworks: Challenges and Opportunities, arXiv:1411.4214v1 [cs.ET] (2014).

Luo J., Li G., Song D., Liang C., Integrating Functional and Topological Properties to Identify Biological Network Motif in Protein Interaction Networks, J. Comput. Theor. Nanosci., 11, 744-750 (2014).

Mandelbrot B.B., The Fractal Geometry of Nature (Updated and Augm. Ed.), New York, W. H. Freeman (1983).

Mitchell M., Complexity: A Guided Tour, Oxford, Oxford University Press (2009).

Nottale L., Fractal Space-Time and Microphysics: Towards a Theory of Scale Relativity, Singapore, World Scientific (1993).

Nottale L., Scale Relativity Theory and Integrative Systems Biology: 2 Macroscopic Quantum-Type Mechanics, Progress in Biophysics and Molecular Biology, 97, 115-157 (2008).

Nottale L., Scale Relativity and Fractal Space-Time - A New Approach to Unifying Relativity and Quantum Mechanics, London, Imperial College Press (2011).

Nottale L., Macroscopic Quantum-Type Potentials in Theoretical Systems Biology, Cells, 1, 1-34 (2013).

Pierobon M., Akyildiz I., A Physical End-to-End Model for Molecular Communication in NanoNetworks, IEEE Journal on Selected Areas in Communications, 28, 602-611 (2010).

Romond P.C., Rustici M., Gonze D., Goldbeter A., Alternating Oscillations and Chaos in a Model of Two Coupled Biochemical Oscillators Driving Successive Phases of the Cell Cycle, Ann NY Acad Sci, 879, 180-193 (1999).

Rusu V., Medical Dictionary (in Romanian), Iaşi, Medical Publishing House (2007).

Serban D.N., Serban I.L., Bild W., Human Physiology. The Cell and the Internal Medium (in Romanian), Iaşi, PIM (2008).

Stefanescu C., Rusu V., Biophysics and Medical Physics: An Introduction, Iaşi, Tehnopress (2008).

Winfree A.T., The Geometry of Biological Time, $2^{\text {nd }}$ Ed., New York, Springer (2000).

\section{HAOS ȘI AUTOSTRUCTURARE ÎN SISTEMELE BIOLOGICE}

(Rezumat)

În prezenta lucrare sunt analizate unele dinamici ale sistemelor biologice, pe baza ipotezei că unităţile structurale ale unui sistem complex, asimilat unei structuri 
biologice, se deplasează pe curbe continue și nediferențiabile (curbe fractale). Acest model teoretic arată faptul că, în aceste sisteme, se pot observa oscilații induse de fenomenul de autosimilaritate, care este un fenomen specific obiectelor fractale. Mai mult, se prezintă unele aplicații potențiale ale proprietății de interferență a sistemelor biologice în unele domenii interdisciplinare de actualitate, cum ar fi comunicarea moleculară. 